\title{
Tropical spastic paraparesis
}

INSERM

\section{Source}

INSERM. (1999). Orphanet: an online rare disease and orphan drug data base. Tropical spastic paraparesis. ORPHA:289326

Tropical spastic paraparesis is a chronic systemic immune-mediated inflammatory myeloneuropathy, more frequently reported in women than in men, that usually presents in adulthood with slowly progressive spastic paraparesis of the lower limbs, bladder and bowel dysfunction, and sensory disturbances in the lower extremities (e.g. paresthesia and dysesthesia) and that is associated with a human T-cell lymphotropic virus type 1 (HTLV-1) infection. 